\title{
Use of noninvasive methods in evaluation of left ventricular performance in coronary artery disease II: Change in systolic time intervals after coronary artery bypass in patients with stable angina
}

\author{
Ronald Meng, Philip R. Liebson, Charles Hollander, Julio C. Teran, and Vincent Barresi ${ }^{1}$ \\ From the Section of Cardiology, Department of Medicine, Rush-Presbyterian-St. Luke's Medical Center, \\ and Rush Medical College, Chicago, Illinois 60612, U.S.A.
}

Serial recording of systolic time intervals (STI) was used to assess changes in left ventricular (LV) function in 92 patients with stable angina undergoing coronary angiography and LV cineangiography. On the basis of angiography, patients were placed in the following study groups : mild or absent coronary artery disease group -21 patients with less than 70 per cent occlusion of all coronary arteries, considered to have non-significant coronary artery disease and not needing bypass surgery; surgical bypass group -52 patients with evidence of significant (>70\%) obstruction of at least one coronary artery who underwent myocardial revascularization; and medical group-19 patients with evidence of significant coronary artery disease not undergoing bypass surgery.

Measured STI, corrected for heart rate and sex, were expressed as indices. No significant differences were noted in the mean STI from the time of initial evaluation to second evaluation 3 to 6 months later in either the mild or absent coronary artery disease patients or the medical group. In the surgical bypass group, however, serial studies at initial angiographic evaluation and 3 to 6 months after bypass surgery showed a shortened pre-ejection period (PEP) from $150 \pm 20$ to $142 \pm 16 \mathrm{~ms}(P<0.001)$, prolonged left ventricular ejection time (LVET) from $396 \pm 21$ to $409 \pm 14 \mathrm{~ms}(P<0 \cdot 02)$, and decreased $P E P / L V E T$ from $0 \cdot 45 \pm 0 \cdot 11$ to $0.40 \pm 0.07(P<0.02)$. Paired data analysis of the three groups also showed a significant change only within the surgical bypass group from initial to final study, with a shortened $P E P(P<0.002)$, prolonged LVET $(P<0.001)$, and decreased PEP/LVET $(P<0.001)$.

These data suggest improvement in $L V$ function in patients with significant coronary artery disease within a few months of myocardial revascularization, without demonstrable change in STI in those patients with coronary artery disease not subjected to revascularization.

Myocardial revascularization procedures have two important goals: (1) to relieve anginal pain and (2) to maintain myocardial viability and possibly to improve left ventricular (LV) performance (Johnson and Kayser, 1963; Kirklin, 1973). It is well established that such revascularization procedures relieve anginal pain in most patients with significant coronary artery obstruction (Mitchel et al., 1970; Spencer et al., 1971; Morris et al., 1972). Long-term follow-up studies have provided conflicting results

Received 21 April 1976

${ }^{1}$ Present address: Northwestern Memorial Hospital, Chicago, Illinois. as to the effect of surgery upon $\mathrm{LV}$ performance, but some have shown that, with maintained graft patency, performance may improve (Saltiel et al., 1970; Manley et al., 1970; Manley and Johnson, 1972; Chatterjee et al., 1972; Griffith et al., 1973).

The most direct means of serially evaluating $\mathrm{LV}$ function after bypass has been by LV catheterization and cineangiography (Rutherford et al., 1972; Hammermeister et al., 1974). This approach has not been routinely used, however, because of such considerations as lack of symptoms, the minor but definite risk that catheterization holds, or because of refusal of the patient to submit to re-examination 
by this technique.

It is clear that reliable information about LV performance obtained non-invasively would be valuable in the follow-up of patients with coronary artery disease after bypass procedures because this approach would allow convenient and frequent study without risk to the patient. One such approach involves the use of indirectly determined systolic time intervals (STI), which have been shown reliably to reflect angiographic and haemodynamic changes in LV performance (Weissler, Harris, and White, 1963; Weissler, Harris, and Schoenfeld, 1968; Garrard, Weissler, and Dodge, 1970; Martin et al., 1971). STI have been shown previously to be useful in serially assessing change in performance in coronary artery disease (Diamant and Killip, 1970; Pouget et al., 1971; Hodges et al., 1972).

This study was designed to investigate the effect of aortocoronary bypass on LV performance in patients with stable angina using serial STI determination, and to compare changes in this surgical group with serial STI in a group of patients with signicant coronary artery disease not subject to surgical intervention.

\section{Subjects and methods}

One hundred and thirteen patients with chest pain suggesting possible coronary artery disease who were evaluated in the catheterization laboratory of RushPresbyterian-St. Luke's Medical Center underwent STI determination immediately before coronary and left ventricular cineangiography. Of these, 92 who completed re-evaluation by STI from 3 to 6 months after initial study were included in the assessment (Table 1).

\section{Cineangiographic study}

All patients underwent selective coronary and left ventricular cineangiography according to the techniques of Sones and Shirey (1962) and Lehman, Debbas, and Boyle (1963), respectively. Angiographic evidence of greater than $\mathbf{7 0}$ per cent arterial obstruction of any major coronary artery was considered to document significant vessel disease (Wégria et al., 1949), and a significant left main coronary artery lesion was considered to represent two vessel disease.

\section{Systolic time interval determination}

STI were measured from the simultaneous recording of the electrocardiogram, phonocardiogram, and indirect carotid artery pulse tracing by the ElemaSchonander Mingograf ink-jet recording system at a paper speed of $100 \mathrm{~mm} / \mathrm{s}$, using previously de-
TABLE 1 Patient studies in each group with exclusions after initiation of study

\begin{tabular}{|c|c|c|c|}
\hline Group & $\begin{array}{l}\text { No. of } \\
\text { patients }\end{array}$ & $\begin{array}{l}\text { No. } \\
\text { excluded }\end{array}$ & $\begin{array}{l}\text { Reason for } \\
\text { exclusion }\end{array}$ \\
\hline $\begin{array}{c}\text { OV } \\
\text { CADm: }\end{array}$ & 25 & 4 & 4-NR \\
\hline & $\begin{array}{r}10 \\
6\end{array}$ & $\begin{array}{l}3 \\
1\end{array}$ & $\begin{array}{l}\text { 2-NR, 1-D } \\
1-N R\end{array}$ \\
\hline $3 \mathrm{~V}$ & 7 & - & - \\
\hline Total CADm & 23 & 4 & 3-NR, 1-D \\
\hline \multicolumn{4}{|l|}{ CADs: } \\
\hline 1V & 15 & 2 & $1-N R, 1-D$ \\
\hline $2 \mathrm{~V}$ & 29 & 7 & 6-NR, $1-\mathrm{D}$ \\
\hline $3 V$ & 21 & 4 & 3-NR, 1-D \\
\hline Total CADs & 65 & 13 & $10-N R, 3-D$ \\
\hline Total & 113 & 21 & 17-NR, 4-D \\
\hline
\end{tabular}

Abbreviations: $0 \mathrm{~V}=$ mild or absent coronary artery obstruction ( $<\mathbf{7 0} \%$ occlusion); CADm $=$ significant coronary artery disease treated medically ( $>70 \%$ occlusion); CADs $=$ significant coronary artery disease treated surgically $(>70 \%$ occlusion); $1 \mathrm{~V}=$ one-vessel disease; $2 \mathrm{~V}=$ two-vessel disease; $3 \mathrm{~V}=$ three-vessel disease; $\mathrm{NR}=$ did not return for follow-up study. $\mathrm{D}=$ died before follow-up period.

scribed techniques (Weissler and Garrard, 1971; Meng et al., 1975). The STI determined included total electromechanical systole $\left(Q-S_{2}\right)$; left ventricular ejection time (LVET); and pre-ejection period (PEP), obtained by subtracting LVET from

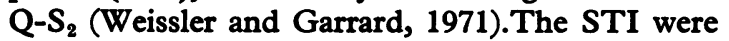
then corrected for heart rate and sex according to the regression equations of Weissler, thus yielding the indices Q-S $\mathrm{S}_{2}$, PEPI, LVETI (Garrard et al., 1970). The indices were used as the final determinants of values, with the exception of the PEP/ LVET ratio which was determined by dividing the uncorrected values of these time intervals.

\section{Patient groups}

Optimal management for each patient was determined jointly by cardiologists and cardiovascular surgeons after consideration of clinical, angiographic, and haemodynamic data according to commonly accepted criteria. Specifically, congestive heart failure was not considered a strict contraindication to bypass surgery. Those patients satisfying the criteria received surgery, and all other patients received medical management.

On the basis of the results of angiography, three selected groups were considered for evaluation.

(1) Mild or absent coronary artery obstruction These patients were found to have less than 70 per 
cent obstruction of all coronary arteries, and thus did not need bypass procedures (21 patients).

(2) Coronary artery disease treated medically These patients had significant $(>70 \%$ ) obstruction in at least one coronary artery, and were treated medically (19 patients: 11 of these patients had poor distal perfusion, and 8 were considered not to have severe enough symptoms to warrant surgery).

(3) Coronary artery disease treated surgically These patients had significant $(>70 \%)$ obstruction in at least one coronary artery, and were treated by myocardial revascularization, which was performed by either reverse saphenous vein or internal mammary artery grafting (52 patients). Gas endarterectomy was infrequently used, and 2 cases required left ventricular myocardial plastic procedures. The vessels bypassed in relation to the number of vessels with significant obstruction are listed in Table 2.

Groups 2 and 3 were further subdivided according to number of coronary arteries significantly obstructed (one, two, or three vessels $=1 \mathrm{~V}, 2 \mathrm{~V}$, and 3V).

\section{Serial studies}

STI were performed initially at time of angiography (Period 1), and again 3 to 6 months later (Period 2).
TABLE 2 Bypass procedures performed

\begin{tabular}{lllll}
\hline \multirow{2}{*}{ Group } & \multirow{2}{*}{ No. of patients } & \multicolumn{4}{c}{ Vessels bypassed } \\
& & 1 & 2 & 3 \\
\hline IV & 13 & 13 & & \\
2V & 22 & $7 \star$ & 15 & \\
3V & 17 & 3 & 12 & 2 \\
\hline Total & 52 & 23 & 27 & 2 \\
\hline
\end{tabular}

*One patient had ventricular septal defect repair, and one patient had resection left ventricular aneurysm.

Abbreviations : $1 \mathrm{~V}=$ one-vessel disease $; 2 \mathrm{~V}=$ two-vessel disease; $3 \mathrm{~V}=$ three-vessel disease.

Surgical bypass was performed within two weeks of angiography and initial STI determination.

Data analysis was performed with the aid of an Olivetti Underwood Programma 101 computer and Monroe Electronics Programmable Statistical Calculator, using Student's $t$ test, both independent and $\chi^{2}$ analysis.

\section{Results}

\section{Clinical data (Table 3)}

After the initial evaluation of 113 patients, 21 did not undergo serial evaluation for the reasons shown in Table 1 . There was no difference in mean age in

TABLE 3 Clinical evaluation of patient groups in study (92 patients)

\begin{tabular}{|c|c|c|c|c|c|c|c|c|c|c|}
\hline \multirow[t]{2}{*}{ Group } & \multirow{2}{*}{$\begin{array}{l}\text { No. of } \\
\text { patients }\end{array}$} & \multirow[t]{2}{*}{$\operatorname{Age}(y)^{\star}$} & \multirow[t]{2}{*}{ Period } & \multirow{2}{*}{\multicolumn{2}{|c|}{ Clinical findings }} & \multicolumn{3}{|c|}{ Medications } & \multicolumn{2}{|c|}{ Prior acute myocardial infarctions } \\
\hline & & & & $A P$ & & $P$ & $D$ & $A R$ & No. of pts. & No. of infarcts \\
\hline \multirow[t]{2}{*}{ OV } & \multirow[t]{2}{*}{21} & \multirow[t]{2}{*}{$48 \pm 9$} & \multirow{2}{*}{$\begin{array}{l}1 \\
2 .\end{array}$} & \multirow{2}{*}{$\begin{array}{l}21 \\
13 \\
\end{array}$} & \multirow{2}{*}{$\begin{array}{l}3 \\
7 \\
\end{array}$} & \multirow{2}{*}{$\begin{array}{l}2 \\
5 \\
\end{array}$} & \multirow{2}{*}{$\begin{array}{l}3 \\
2\end{array}$} & \multirow{2}{*}{$\begin{array}{l}0 \\
0\end{array}$} & \multirow[t]{2}{*}{1} & \multirow[t]{2}{*}{4} \\
\hline & & & & & & & & & & \\
\hline \multicolumn{11}{|l|}{ CADm: } \\
\hline \multirow{2}{*}{ IV } & \multirow[t]{2}{*}{7} & \multirow{2}{*}{$50 \pm 6$} & 1 & 7 & 0 & 1 & 2 & 0 & \multirow[t]{2}{*}{4} & \multirow[t]{2}{*}{5} \\
\hline & & & 2 & 7 & 0 & 0 & 0 & 1 & & \\
\hline \multirow[t]{2}{*}{$2 \mathrm{~V}$} & \multirow[t]{2}{*}{5} & \multirow[t]{2}{*}{$56 \pm 7$} & 1 & 5 & 1 & 0 & 0 & 0 & \multirow[t]{2}{*}{4} & \multirow[t]{2}{*}{5} \\
\hline & & & 2 & 5 & 1 & 3 & 2 & 0 & & \\
\hline \multirow[t]{2}{*}{$3 \mathrm{~V}$} & \multirow[t]{2}{*}{7} & \multirow[t]{2}{*}{$52 \pm 10$} & 1 & 7 & 2 & 1 & 2 & 1 & \multirow[t]{2}{*}{4} & 8 \\
\hline & & & 2 & 6 & 5 & 3 & 4 & 1 & & \\
\hline Total CADm & 19 & $52 \pm 8$ & 1 & 19 & 3 & 2 & 4 & 1 & 13 & 22 \\
\hline & & & 2 & 18 & 6 & 6 & 2 & 2 & & \\
\hline CADs: & & & & & & & & & & \\
\hline IV & 13 & $52 \pm 6$ & 1 & 13 & 1 & 1 & 2 & 0 & 5 & 6 \\
\hline & & & 2 & 0 & 0 & 0 & 0 & 1 & & \\
\hline $2 \mathrm{~V}$ & 22 & $52 \pm 7$ & 1 & 22 & 5 & 1 & 5 & 4 & 12 & 15 \\
\hline & & & 2 & 4 & 1 & 1 & 6 & 2 & & \\
\hline $3 \mathrm{~V}$ & 17 & $54 \pm 8$ & 1 & 17 & 4 & 2 & 2 & 1 & 12 & 19 \\
\hline & & & 2 & 1 & 2 & 0 & 7 & 2 & & \\
\hline Total CADs & 52 & $53 \pm 7$ & 1 & 52 & 10 & 4 & 9 & 5 & 29 & 40 \\
\hline & & & 2 & 5 & 4 & 1 & 13 & 5 & & \\
\hline
\end{tabular}

$\star$ Mean \pm 1 SD.

Abbreviations: $\mathrm{AP}=$ anginal pain $; \mathrm{CHF}=$ congestive heart failure; $\mathrm{P}=$ propranolol; $\mathrm{D}=$ digitalis; $\mathrm{AR}=$ antiarrhythmics (quinidine or procainamide). For other abbreviations see footnote to Table 1 . 
all 3 groups. All patients were admitted to the study because of anginal symptoms at the time of initial evaluation. At the time of follow-up, 62 per cent of the mild or absent coronary artery disease group still had anginal symptoms as did 95 per cent of the medically treated group, but only 10 per cent of the surgical bypass group complained of angina. Clinical evidence of congestive heart failure increased slightly in the mild or absent, and medically treated groups but decreased in the surgical bypass group.

The percentage of patients in each group receiving digitalis initially varied from 14 to 21 per cent. At follow-up, there was a decrease in this percentage to 10 per cent in both the mild or absent, and medically treated groups. The surgical bypass group, however, increased its digitalis usage to 25 per cent of patients. Propranolol was being administered initially to 4 to 10 per cent of patients in each group. Its use increased to 24 per cent and 30 per cent in the mild or absent, and medically treated groups, respectively, and decreased to 2 per cent in the surgical bypass group. Antiarrhythmic drugs, either quinidine or procainamide, were not administered to the mild or absent coronary artery disease group, but in the medically treated group were administered to 1 patient initially and to 2 patients at follow-up. Five patients in the surgical bypass group received these agents both at the beginning and end of the study.

Evidence for previous infarction was found in 5 per cent of the mild or absent group, 68 per cent of the medically treated group and 56 per cent of the surgical bypass group. None of the patients in the final study groups developed infarction during the course of the study.

\section{Changes in mean STI values: intragroup comparisons (Table 4)}

Comparison of mean values between Periods 1 and 2 for each group and subgroup showed no significant change for the mild or absent coronary artery disease group or the medically treated group. The surgical bypass group, however, showed a significantly increased LVETI from $396 \pm 21 \mathrm{~ms}$ to $409 \pm 14 \mathrm{~ms}(P<0.001)$, decreased PEPI from $150 \pm 20$ to $142 \pm 16 \mathrm{~ms}(P<0.02)$, and a decreased PEP/LVET from $0.45 \pm 0.11$ to $0.40 \pm 0.07$ $(P<0.02)$. When surgical subgroups were studied, LVETI increased significantly in $2 \mathrm{~V}$ and $3 \mathrm{~V}$ patients, and PEPI and PEP/LVET decreased significantly in $2 \mathrm{~V}$ patients.

Paired $t$ test analysis showed no significant change in the absent or mild disease group and the medically treated groups, but a significant increase in
LVET $(P<0.001)$ and decrease in PEPI $(P<0.002)$ and PEP/LVET $(\mathrm{P}<0.001)$ in the surgical bypass group (Table 5).

\section{Intergroup comparisons: period 1}

Comparison between the medically treated group and the mild or absent coronary artery disease groups showed a significantly greater PEP/LVET in the medically treated group $(P<0.05)$. There were no differences when medical subgroups were compared with the mild or absent coronary artery disease group. The surgical bypass group had a shorter LVETI and greater PEP/LVET than the absent or mild group $(P<0.05)$ for both comparisons, with significant differences in subgroups also (Table 4). There was no significant difference between the medical group, and surgical bypass groups in any STI.

\section{Intergroup comparisons: period 2}

No significant differences were found between the 3 groups.

\section{Discussion}

Our results show the considerable improvement in symptoms of angina after revascularization seen in other studies (Griffith et al., 1973; Hammermeister et al., 1974). The findings of improvement in STI in the 3 to 6 month follow-up after bypass surgery also suggests an improvement in myocardial function.

It would not be expected that patients in the medically treated group would improve $\mathrm{LV}$ function at follow-up evaluation, as is shown by the lack of significant improvement of STI in that group. It is true, however, that had this patient group been larger, significant changes might have been realized. The absent or mild disease group, with lack of significant coronary artery disease (less than $70 \%$ occlusion of any major vessel), showed insignificant change in serial STI studies. It might be argued that this group could in fact manifest ischaemia as a result of small vessel disease, but initial LVETI and PEP/LVET in this group were significantly less abnormal than those of the surgical group during the initial study. In serial study, the STI in the surgical bypass group returned to normal significantly more than either the mild or absent coronary artery disease group or the medical group. This is because of the more abnormal initial values in the surgical bypass group. Individual group mean STI values appeared to reflect myocardial function abnormalities by objective measurement of left ventricular function, as has been 
TABLE 4 Systolic time intervals

\begin{tabular}{|c|c|c|c|c|c|c|}
\hline Group & No. of patients & Period & $Q-S_{2} I^{\star}(m s)$ & $P E P I^{\star}$ (ms) & $L V E T I^{\star}(\mathrm{ms})$ & $P E P / L V E T^{\star}$ \\
\hline OV & 21 & $\begin{array}{l}1 \\
2\end{array}$ & $\begin{array}{l}555 \pm 19 \\
548 \pm 17\end{array}$ & $\begin{array}{l}140 \pm 20 \\
143 \pm 21\end{array}$ & $\begin{array}{l}408 \pm 21 \\
414 \pm 17\end{array}$ & $\begin{array}{l}0.38 \pm 0.07 \\
0.40 \pm 0.09\end{array}$ \\
\hline \multicolumn{7}{|l|}{ CADm: } \\
\hline IV & 7 & $\begin{array}{l}1 \\
2\end{array}$ & $\begin{array}{l}543 \pm 24 \\
555 \pm 23\end{array}$ & $\begin{array}{l}143 \pm 20 \\
146 \pm 13\end{array}$ & $\begin{array}{l}399 \pm 10 \\
409 \pm 16\end{array}$ & $\begin{array}{l}0.42 \pm 0.09 \\
0.40 \pm 0.05\end{array}$ \\
\hline $2 \mathrm{~V}$ & 5 & $\begin{array}{l}1 \\
2\end{array}$ & $\begin{array}{l}559 \pm 23 \\
563 \pm 16\end{array}$ & $\begin{array}{l}151 \pm 16 \\
150 \pm 25\end{array}$ & $\begin{array}{l}393 \pm 32 \\
412 \pm 16\end{array}$ & $\begin{array}{l}0.47 \pm 0.11 \\
0.42 \pm 0.11\end{array}$ \\
\hline $3 \mathrm{~V}$ & 7 & $\begin{array}{l}1 \\
2\end{array}$ & $\begin{array}{l}543 \pm 21 \\
542 \pm 16\end{array}$ & $\begin{array}{l}148 \pm 22 \\
141 \pm 28\end{array}$ & $\begin{array}{l}394 \pm 22 \\
400 \pm 22\end{array}$ & $\begin{array}{l}0.46 \pm 0.12 \\
0.41 \pm 0.12\end{array}$ \\
\hline Total CADm & 19 & $\begin{array}{l}1 \\
2\end{array}$ & $\begin{array}{l}547 \pm 23 \\
552 \pm 20\end{array}$ & $\begin{array}{l}147 \pm 19 \\
146 \pm 22\end{array}$ & $\begin{array}{l}396 \pm 21 \\
406 \pm 18\end{array}$ & $\begin{array}{l}0.44 \pm 0.10 \\
0.41 \pm 0.09\end{array}$ \\
\hline \multicolumn{7}{|l|}{ CADs: } \\
\hline IV & 13 & $\begin{array}{l}1 \\
2\end{array}$ & $\begin{array}{l}542 \pm 25 \\
554 \pm 13\end{array}$ & $\begin{array}{l}144 \pm 19 \\
143 \pm 11\end{array}$ & $\begin{array}{l}398 \pm 16 \\
411 \pm 12\end{array}$ & $\begin{array}{l}0.40 \pm 0.09 \\
0.40 \pm 0.05\end{array}$ \\
\hline $2 \mathrm{~V}$ & 22 & $\begin{array}{l}1 \\
2\end{array}$ & $\begin{array}{l}547 \pm 25 \\
548 \pm 18\end{array}$ & $\begin{array}{l}148 \pm 18 \\
138 \pm 17\end{array}$ & $\begin{array}{l}398 \pm 25 \\
411 \pm 13\end{array}$ & $\begin{array}{l}0.45 \pm 0.11 \\
0.38 \pm 0.07\end{array}$ \\
\hline $3 \mathrm{~V}$ & 17 & $\begin{array}{l}1 \\
2\end{array}$ & $\begin{array}{l}548 \pm 23 \\
553 \pm 21\end{array}$ & $\begin{array}{l}156 \pm 20 \\
147 \pm 17\end{array}$ & $\begin{array}{l}392 \pm 19 \\
406 \pm 17\end{array}$ & $\begin{array}{l}0.48 \pm 0.11 \\
0.43 \pm 0.08\end{array}$ \\
\hline Total CADs & 52 & $\begin{array}{l}1 \\
2\end{array}$ & $\begin{array}{l}546 \pm 24 \\
551 \pm 18\end{array}$ & $\begin{array}{l}150 \pm 20 \\
142 \pm 16\end{array}$ & $\begin{array}{l}396 \pm 21 \\
409 \pm 14\end{array}$ & $\begin{array}{l}0.45 \pm 0.11 \\
0.40 \pm 0.07\end{array}$ \\
\hline
\end{tabular}

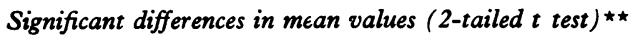

\begin{tabular}{|c|c|c|c|c|}
\hline & $Q-S_{2} I^{\star}(m s)$ & $P E P I^{\star}(m s)$ & $L V E T I^{\star}(m s)$ & $P E P / L V E T^{\star}$ \\
\hline \multicolumn{5}{|l|}{ Period 1 vs. Period 2} \\
\hline oV & \multirow{3}{*}{\multicolumn{4}{|c|}{$\begin{array}{l}\text { All not significant } \\
\text { All not significant }\end{array}$}} \\
\hline CADm & & & & \\
\hline \multicolumn{2}{|l|}{ CAD: } & & & \\
\hline $1 \mathrm{~V}$ & NS & NS & NS & NS \\
\hline $2 \mathrm{~V}$ & NS & $<0.05$ & $<0.05$ & $<0.05$ \\
\hline $3 \mathrm{~V}$ & NS & NS & $<0.05$ & NS \\
\hline Total CADs & NS & $<0.02$ & $<0.001$ & $<0.02$ \\
\hline \multicolumn{5}{|l|}{ Period 1} \\
\hline CADm vs. CADs & \multirow{3}{*}{\multicolumn{4}{|c|}{$\begin{array}{l}\text { All not significant } \\
\text { All not significant }\end{array}$}} \\
\hline CADm vs. OV & & & & \\
\hline CADs vs. 0V: & & & & \\
\hline $1 \mathrm{~V}$ vs. $0 \mathrm{~V}$ & NS & NS & NS & NS \\
\hline $2 \mathrm{~V}$ vs. $0 \mathrm{~V}$ & NS & NS & NS & $<0.025$ \\
\hline $3 \mathrm{~V}$ vs. $0 \mathrm{~V}$ & NS & $<0.02$ & $<0.02$ & $<0.005$ \\
\hline Total CADs vs. OV: & NS & NS & $<0.05$ & $<0.05$ \\
\hline \multicolumn{5}{|l|}{ Period 2} \\
\hline CADm vs. CADs & \multirow{3}{*}{\multicolumn{4}{|c|}{$\begin{array}{l}\text { All not significant } \\
\text { All not significant } \\
\text { All not significant }\end{array}$}} \\
\hline CADm vs. OV & & & & \\
\hline CADs vs. OV & & & & \\
\hline
\end{tabular}

$\star$ Mean values $\pm 1 \mathrm{SD}$.

$\star \star \mathbf{P}$ values.

Abbreviations: $\mathrm{Q}-\mathrm{S}_{2} \mathrm{I}=$ total electromechanical systole index; $\mathrm{PEPI}=$ pre-ejection period index; $\mathrm{LVETI}=$ left ventricular ejection time index; PEP/LVET = ratio of uncorrected intervals; NS = not significant. 
TABLE 5 Changes in systolic time intervals from Period 1 to Period 2*

\begin{tabular}{|c|c|c|c|c|c|}
\hline Group & No. of patients & $P E P I \star \star(m s)$ & $L V E T I \star \star(m s)$ & $Q-S 21 \star \star(m s)$ & $P E P / L V E T^{\star \star}$ \\
\hline ov & 21 & $\begin{array}{r}-3 \cdot 33 \\
\text { NS }\end{array}$ & $\begin{array}{c}+5.66 \\
\text { NS }\end{array}$ & $\begin{array}{r}+6 \cdot 87 \\
\text { NS }\end{array}$ & $\begin{array}{r}+1.52 \\
\text { NS }\end{array}$ \\
\hline CADm & 19 & $-1 \cdot 47$ & $\begin{array}{l}+5.68 \\
\text { NS }\end{array}$ & $+5 \cdot 16$ & -3.47 \\
\hline CADs & 52 & $\begin{array}{l}\text { NS } \\
-7.71 \\
\mathrm{P}<0.002\end{array}$ & $\begin{array}{c}\text { NS } \\
+12.81 \\
P<0.001\end{array}$ & $\begin{array}{r}N S \\
+5 \cdot 21 \\
\text { NS }\end{array}$ & $\begin{array}{c}\text { NS } \\
-4.48 \\
P<0.001\end{array}$ \\
\hline
\end{tabular}

$\star$ Paired $\mathrm{t}$ test.

$\star \star$ Mean change of paired values.

Abbreviations: For abbreviations, see previous tables.

previously shown. There was, however, considerable overlap in individual STI values, indicating that one determination may not allow exact quantification of the degree of left ventricular dysfunction. A more valuable and reliable use of STI may be examination of serial changes in STI in the individual patient.

It has been shown that externally determined STI quite reliably reproduces internally determined STI (Weissler et al., 1963; Martin et al., 1971). One factor limiting usefulness of STI, however, is that they are quite sensitive to pharmacological interventions and spontaneous left ventricular function changes such as in an anginal attack and with use of digitalis (Pouget et al., 1971; Weissler and Garrard, 1971). We can minimize pharmacological intervention as a cause of the changes in mean STI values in the surgical group. Antiarrhythmics were used only in an insignificant proportion, and the number of patients on propranolol and digitalis in each group did slightly change. However, the significant changes in STI from period 1 to period 2 in the surgical group and the significant difference between the surgical and medical groups were not those expected from changes in drugs alone. Medicines complicate this analysis, but are an important aspect of management. Thus, patients were not excluded because they were on drug therapy.

Objective post-surgical evaluation has been made by other groups using cineangiography, evaluation of LV haemodynamics, and exercise studies (Manley et al., 1970; Manley and Johnson, 1972; Bourassa et al., 1972; Anderson, 1972; Chatterjee et al., 1972, 1973; Griffith et al., 1973; Lapin et al., 1973; Alderman et al., 1973; Bartel et al., 1973). Chatterjee et al. (1973) showed that two weeks after bypass, coronary artery disease patients with chronic ischaemia had improved wall motion. Manley and Johnson (1972) studied patients before and three months after bypass surgery and showed an improvement in function related to graft patency.
On the other hand, Arbogast, Solignac, and Bourassa (1973) showed no improvement in ejection fraction with patent grafts and a worsening with severely stenosed grafts one year after surgery. Hammermeister et al. (1974) showed no significant changes in LV volume measurements in the group as a whole or in the subgroup with patent grafts 1 to 14 months after surgery, despite improvement in symptomatology and exercise performance. In patients studied 2 weeks and 1 year after bypass, Bourassa et al. (1972) showed an improvement of left ventricular wall motion in only one-half and an increased abnormality of wall motion in over 40 per cent with inadequate patency, compared with preoperative studies.

As for the STI changes after bypass, Johnson et al. (1972), in a study of 11 patients 3 months after bypass, showed a decreased PEPI, increased LVETI, and decreased PEP/LVET compared with preoperative studies, similar to our results.

In conclusion, serial STI showed improvement in PEPI, LVETI, and PEP/LVET in a group of surgical patients in the 3- to 6-month period after bypass surgery. This improvement was found neither in patients with coronary artery disease not subjected to surgery nor in patients with anginal symptoms with less than significant coronary artery obstruction. This suggests an improvement of function, and the high follow-up rate of patient re-evaluation suggests that serial STI may be valuable as a large-scale determinant of $L V$ per formance after surgery.

The authors thank Mr. Mitchell Passovoy for his assistance with statistical analysis.

\section{References}

Alderman, E. L., Matlof, H. J., Wexler, L., Shumway, N. E., and Harrison, D. C. (1973). Results of direct coronaryartery surgery for the treatment of angina pectoris. New England fournal of Medicine, 288, 535. 
Anderson, R. P. (1972). Effects of coronary bypass graft occlusion on left ventricular performance. Circulation, 46, 507.

Arbogast, R., Solignac, A., and Bourassa, M. G. (1973). Influence of aor tocoronary saphenous vein bypass surgery on left ventricular volumes and ejection fraction. American Fournal of Medicine, 54, 290.

Bartel, A. G., Behar, V. S., Peter, R. H., Orgain, E. S., and Kong, Y. (1973). Exercise stress testing in evaluation of aortocoronary bypass surgery: report of 23 patients. Circulation, 48, 141.

Bourassa, M. G., Lespérance, J., Campeau, L., and Saltiel, J. (1972). Fate of left ventricular contraction following aortocoronary venous grafts. Circulation, 46, 724.

Chatterjee, K., Swan, H. J. C., Parmley, W. W., Sustaita, H., Marcus, H., and Matloff, J. (1972). Depression of left ventricular function due to acute myocardial ischemia and its reversal after aortocoronary saphenous-vein bypass. New England Fournal of Medicine, 286, 1117.

Chatterjee, K., Swan, H. J. C., Parmley, W. W., Sustaita, H., Marcus, H. S., and Matloff, J. (1973). Influence of direct myocardial revascularization on left ventricular asynergy and function in patients with coronary heart disease. Circulation, 47, 276.

Diamant, B., and Killip, T. (1970). Indirect assessment of left ventricular performance in acute myocardial infarction. Circulation, 42, 579.

Garrard, C. L., Jr., Weissler, A. M., and Dodge, H. T. (1970). The relationship of alterations in systolic time intervals to ejection fraction in patients with cardiac disease. Circulation, 42, 455.

Griffith, L. S. C., Achuff, S. C., Conti, C. R., Humphries, J. O., Brawley, R. K., Gott, V. L., and Ross, R. S. (1973). Changes in intrinsic coronary circulation and segmental ventricular motion after saphenous-vein coronary bypass graft surgery. New England fournal of Medicine, 288, 589.

Hammermeister, K. E., Kennedy, J. W., Hamilton, G. W., Stewart, D. K., Gould, K. L., Lipscomb, K., and Murray, J. A. (1974). Aortocoronary saphenous-vein bypass: failure of successful grafting to improve resting left ventricular function in chronic angina. New England Fournal of Medicine, 290, 186.

Hodges, M., Halpern, B. L., Friesinger, G. C., and Dagenais, G. R. (1972). Left ventricular preejection period and ejection time in patients with acute myocardial infarction Circulation, 45, 933.

Johnson, A. D., O'Rourke, R. A., Karliner, J. S., and Burian C. (1972). Effect of myocardial revascularization on systolic time intervals in patients with left ventricular dysfunction. Circulation, 45, Suppl. I, 91.

Johnson, W. D., and Kayser, K. L. (1963). An expanded indication for coronary surgery. Annals of Thoracic Surgery, 16, 1.

Kirklin, J. W. (1973). Evaluating the results of cardiac surgery (Editorial). Circulation, 48, 232.

Lapin, E. S., Murray, J. A., Bruce, R. A., and Winterscheid, L. (1973). Changes in maximal exercise performance in the evaluation of saphenous vein bypass surgery. Circulation, 47, 1164 .

Lehman, J. S., Debbas, J. N., and Boyle, J. J., Jr. (1963). Cardiac ventriculography. American fournal of Roentgenology, 89, 295.

Manley, J. C., and Johnson, W. D. (1972). Effects of surgery on angina (pre- and postinfarction) and myocardial function (failure). Circulation, 46, 1208.
Manley, J. C., Johnson, W. D., Flemma, R. J., and Lepley, D., Jr. (1970). Objective evaluation of the effects of direct myocardial revascularization on ventricular function utilizing ergometer exercise testing (abstract). American Fournal of Cardiology, 26, 648.

Martin, C. E., Shaver, J. A., Thompson, M. E., Reddy, P. S., and Leonard, J. J. (1971). Direct correlation of external systolic time intervals with internal indices of left ventricular function in man. Circulation, 44, 419.

Meng, R., Hollander, C., Liebson, P. R., Teran, J. C., Barresi, V., and Laurie, M. (1975). The use of noninvasive methods in the evaluation of left ventricular performance in coronary artery disease. I. Relation of systolic time intervals to angiographic assessment of coronary artery disease severity. American Heart fournal, 90, 134.

Mitchel, B. F., Adam, M., Lambert, C. J., Sungu, U., and Shiekh, S. (1970). Ascending aorta-to-coronary artery saphenous vein bypass grafts. Fournal of Thoracic and Cardiovascular Surgery, 60, 457.

Morris, G. C., Jr., Reul, G. J., Howell, J. F., Crawford, E. S., Chapman, D. W., Beazley, H. L., Winters, W. L., Peterson, P. K., and Lewis, J. M. (1972). Follow-up results of distal coronary artery bypass for ischemic heart disease. American fournal of Cardiology, 29, 180.

Pouget, J. M., Harris, W. S., Mayron, B. R., and Naughton, J. P. (1971). Abnormal responses of the systolic time intervals to exercise in patients with angina pectoris. Circulation, 43, 289.

Rutherford, B. D., Gau, G. T., Danielson, G. K., Pluth, J. R., Davis, G. D., Wallace, R. B., and Frye, R. L. (1972). Left ventricular haemodynamics before and soon after saphenous vein bypass graft operation for angina pectoris. British Heart fournal, 34, 1156.

Saltiel, J., Lespérance, J., Bourassa, M. G., Castonguay, Y., Campeau, L., and Grondin, P. (1970). Reversibility of left ventricular dysfunction following aorto-coronary bypass grafts. American fournal of Roentgenology, 110, 739.

Sones, F. M., Jr., and Shirey, E. K. (1962). Cine coronary arteriography. Modern Concepts of Cardiovascular Disease, 31, 735.

Spencer, F. C., Green, G. E., Tice, D. A., and Glassman, E. (1971). Bypass grafting for occlusive disease of the coronary arteries: a report of experience with 195 patients. Annals of Surgery, 173, 1029.

Wégria, R., Segers, M., Keating, R. P., and Ward, H. P. (1949). Relationship between the reduction in coronary flow and the appearance of electrocardiographic changes. American Heart fournal, 38, 90.

Weissler, A. M., and Garrard, C. L., Jr. (1971). Systolic time intervals in cardiac disease. Modern Concepts of Cardiovascular Disease, 40, 1.

Weissler, A. M., Harris, L. C., and White, G. D. (1963). Left ventricular ejection time index in man. Fournal of Applied Physiology, 18, 919.

Weissler, A. M., Harris, W. S., and Schoenfeld, C. D. (1968). Systolic time intervals in heart failure in man. Circulation, 37, 149.

Requests for reprints to Dr. Philip R. Liebson, Rush-Presbyterian-St. Luke's Medical Center, 1753 West Congress Parkway, Chicago, Illinois 60612 , U.S.A. 